\title{
Managing challenging behaviour
}

Better

education and care

PHOTO REDACTED DUE TO THIRD PARTY RIGHTS OR OTHER LEGAL ISSUES 
(C) Crown copyright 2005

Document reference number: HMI 2363

Website: www.ofsted.gov.uk

This document may be reproduced in whole or in part for non-commercial educational purposes, provided that the information quoted is reproduced without adaptation, and the source and date of publication are stated. 


\section{Contents}

Executive summary

Main findings

Behaviour: the national picture

Behaviour in the settings visited

Action to manage and improve behaviour

Effective support from other services

Monitoring, evaluating and improving provision 25

Views of children and young people and parents and carers 27 


\section{Executive summary}

This report gives an account of behaviour in schools based on national evidence and provides an analysis of behaviour in a range of educational settings based on visits by Her Majesty's Inspectors (HMI).

The settings included early years provision, mainstream and special schools, pupil referral units (PRUs), secure training centres and colleges. The visits by HMI were informed by research Ofsted commissioned from the University of Birmingham. They set out to establish the types of behaviour that schools and other settings find challenging and to evaluate their responses to it.

Some of the findings in this report are based on a wider range of Ofsted's evidence including that gathered from inspections of behaviour, bullying and minority ethnic achievement; inspections of programmes such as Excellence in Cities and Education Action Zones; local education authority (LEA) inspections; analysis of LEA behaviour support plans; and scrutiny of more than 1,550 reports of inspections of schools that have been inspected at least twice by Ofsted.

The great majority of children and young people enjoy learning, work hard and behave well. Among the schools inspected in 2003/04, behaviour was good or better in $90 \%$ of primary schools, $68 \%$ of secondary schools and $80 \%$ of special schools and PRUs. However, Ofsted's annual reports have highlighted the fact that the behaviour of some pupils, usually boys, remains a serious concern for many schools and other settings. Their behaviour troubles others, affects the climate of the learning community and disrupts their own and others' progress.

Considerable emphasis has been put on inclusion in recent years, exemplified in the revised Special Educational Needs Code of Practice. ${ }^{1}$ A recent Ofsted report, Special educational needs and disability: towards inclusive schools, confirmed that pupils with emotional, behavioural and social difficulties (EBSD) are the most difficult group for schools to manage. Conflicts can arise between meeting individual needs and the efficient education of other children.
Between 2001 and 2003 there was a 25\% increase in the number of pupils educated in PRUs. Between 2001 and 2004 there was a $14 \%$ increase in the number of pupils placed by LEAs in independent special schools catering solely or mainly for pupils with special educational needs (SEN). Most of the pupils admitted to these schools have EBSD or severe learning difficulties (SLD), often with associated challenging behaviour.

As the successful practice described in this report illustrates, schools and other settings can be expected to solve most behaviour problems themselves but they cannot solve them all. They need specialist support from other services. Some schools need to make special provision to cope with poor behaviour and to deploy additional resources to assist whole-school change. The substantial funding which the Department for Education and Skills (DfES) has provided to support provision in schools is proving generally beneficial. 


\section{Main findings}

- The behaviour of the very large majority of pupils and students remains satisfactory or better. Most schools and other settings are successful at managing behaviour and creating an environment in which learners feel valued, cared for and safe.

- The most common form of poor behaviour is persistent, low-level disruption of lessons that wears down staff and interrupts learning. Extreme acts of violence remain very rare and are carried out by a very small proportion of pupils.

- A significant proportion of pupils with difficult behaviour have SEN and face disadvantage and disturbance in their family lives. Many have poor language skills. Problems with reading and writing often begin early and continue into secondary school, limiting achievement in a range of subjects.

- Behaviour is significantly better in settings which have a strong sense of community and work closely with parents. In these settings learners feel safe and are confident that issues such as bullying are dealt with swiftly and fairly.

- A strong lead by senior managers who set high standards and provide close support to staff contributes significantly to the effective management of behaviour.

- Most schools and other settings recognise that an appropriate curriculum and effective teaching engage learners and encourage good behaviour, but about a quarter of those visited in this survey have difficulty in ensuring that their provision meets the standards needed in these respects.

- Staff in some settings require more training in managing and improving the behaviour of more difficult pupils.

- The quality of accommodation has a significant impact on behaviour. Accommodation that is welcoming, stimulating and well maintained tends to foster good behaviour.

- The extent of LEA support for schools in managing more challenging behaviour varies. A common weakness is the lack of detailed evaluation of the benefits of the support given by LEAs.
- LEAs and schools recognise the importance of working with other agencies but less than half have established strong partnerships with health and social services.

- Schools, PRUs and colleges are generally weak at monitoring and evaluating their own strategies and the impact of support from other agencies on the attitudes and behaviour of more difficult pupils.

\section{Recommendations}

Schools, colleges and PRUs should:

- focus on improving the quality of teaching and the provision of an appropriate curriculum that engages the more difficult pupils

- do more to improve the literacy and other communication skills of pupils with difficult behaviour

- improve systems for tracking academic and social development, and make better use of this information to help pupils improve and manage their behaviour

- provide more systematic training for senior managers, teachers and assistants in behaviour management and in child and adolescent development

- review the way they link with parents

- underline the need for consistency among staff in the way expectations of behaviour are set and maintained.

LEAs should:

- monitor and evaluate schools' responses to pupils with more challenging behaviour in order to target support more effectively

- build on initial teacher training in order to provide longterm programmes of professional development in child and adolescent development and on the application of behaviour management strategies

- encourage effective partnerships with other services and create more opportunities for joint training. 


\section{Behaviour: the national picture}

- The great majority of children and young people enjoy learning, work hard and behave well, but the poor behaviour of a small minority continues to present a challenge to schools and other settings.

- Lack of agreed definitions of what constitutes challenging behaviour makes it difficult to gauge the full extent of it. Perception of poor behaviour is conditioned both by the context and by the observer's expectations.

- The challenging behaviour of many younger pupils arises mainly as a result of poor language and social skills and emotional development fitting to their age.

- The most common form of poor behaviour is low-level disruption of lessons, perpetrated much more often by boys than by girls.

\section{Ofsted school inspections}

1. Of all the schools inspected by Ofsted in 2003/04, behaviour was at least satisfactory in over $90 \%$. It was good or better in $68 \%$ of secondary schools, $80 \%$ of special schools and PRUs and $90 \%$ of primary schools.

2. The great majority of pupils enjoy school, work hard and behave well. A strong sense of community and positive engagement with parents are features of schools where behaviour is good.

3. Analysis of inspection judgements since 1996/97 shows that behaviour in primary schools has gradually improved.

Figure 1. Percentage of primary schools where behaviour is judged good or better.

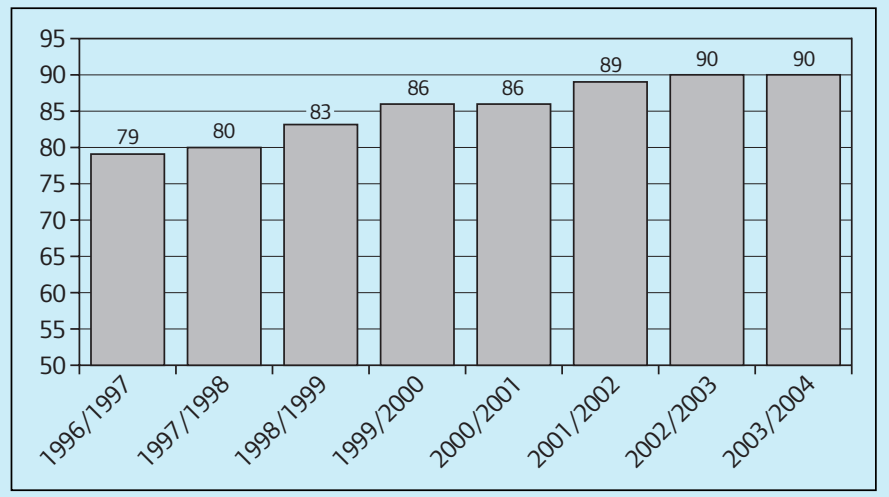

4. By contrast, the proportion of secondary schools in which behaviour overall has been judged good or better has declined since 1996/97 from over three quarters to over two thirds. Over the same period, the proportion where behaviour is unsatisfactory, at just under one in ten schools, has not reduced.

Figure 2. Percentage of secondary schools where behaviour is judged good or better.

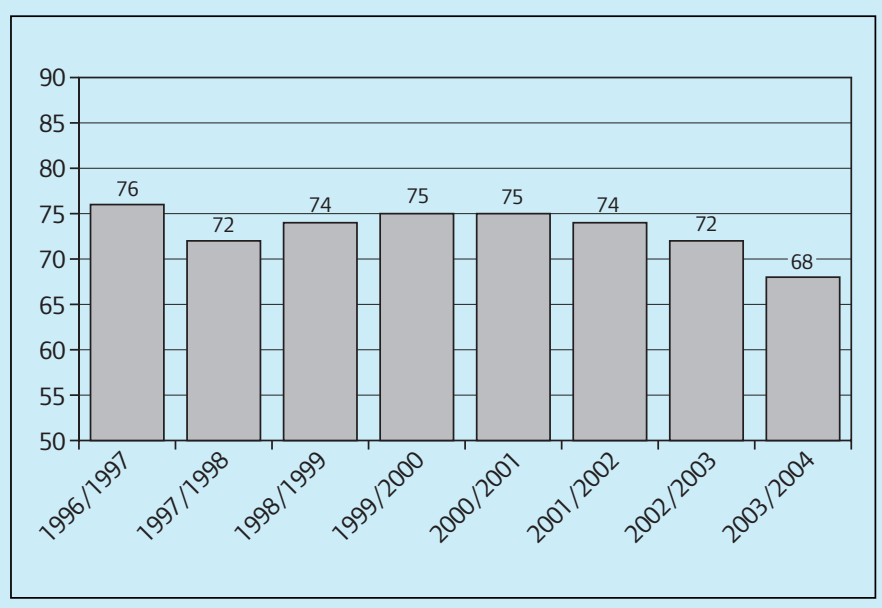

5. Evidence from inspections confirms that the most common form of poor behaviour in schools continues to be that identified by the Elton report: low-level disruption of lessons. ${ }^{2}$ The Elton report detailed what are in themselves minor discipline problems that involve pupils talking out of turn, avoiding work themselves and hindering the work of others, being rowdy and making inappropriate remarks. Such problems continue to feature, to one degree or another, in most schools. While teachers usually deal with such behaviour effectively, the cumulative effect can be frustrating and stressful for both teachers and the generality of pupils.

6. Incidents of verbal and physical abuse aimed at peers and, less frequently, staff by a small proportion of pupils are a problem in most schools. Acts of extreme violence are very rare; they are mostly directed towards other pupils rather than staff. 
7. Incidents of poor behaviour increase with age, rising steeply from the age of 9 . However, $20 \%$ of poor behaviour in primary schools involves pupils aged 4 to 6 years. This group comes to school ill-prepared socially and emotionally. In secondary schools behaviour worsens during Key Stage 3. In 2002/03 the percentage of lessons in which behaviour was unsatisfactory rose from less than $5 \%$ in Year 7 to over $8 \%$ in Years 8 and 9.

\section{School exclusions}

8. The chart below shows the trend in permanent exclusions over a 10-year period.

Figure 3. Permanent exclusions from schools.

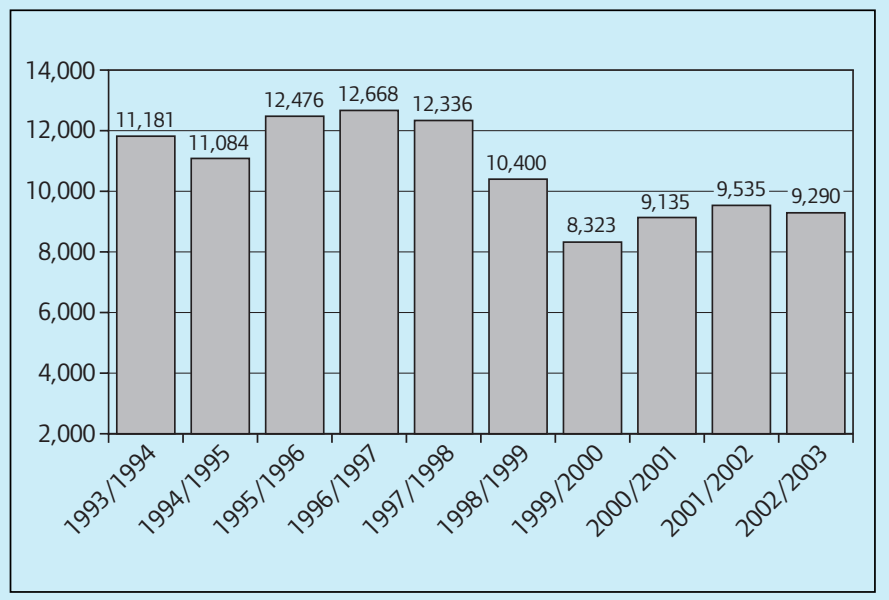

9. The DfES carried out a detailed survey of the extent of and reasons for fixed-term and permanent exclusions for the first time in the summer term of 2003. While there are some concerns about the reliability of the figures provided, they indicate that exclusions involved 62,000 pupils, most of whom had only one fixed period of exclusion; $20 \%$ had two or more.

10. The most common reason for both permanent and fixedterm exclusion, accounting for more than one fifth of all cases, was persistent disruptive behaviour. Assaults against pupils accounted for $14 \%$ of permanent and $16 \%$ of fixedterm exclusions, while assaults against staff accounted for $12 \%$ and $5 \%$ respectively.
11. In primary schools, boys are 10 times more likely than girls to be excluded. In relation to the most challenging behaviour the ratio of boys to girls is twelve to one.

\section{Research evidence}

12. Lack of agreed definitions of what constitutes challenging behaviour in schools makes it difficult to gauge the full extent of it. Some instances of violent behaviour in schools attract considerable media and public attention, but research indicates that such instances are rare. Research suggests that up to $5 \%$ of pupils may display challenging behaviour at some time in their schooling, though by no means all of this behaviour involves violent conduct.

13. Sound international comparisons on the extent and nature of poor behaviour in schools are difficult to come by. Figures for the United States and Canada appear similar to United Kingdom figures. In the United States, incidents involving firearms and other weapons capture attention, but acts of extreme behaviour are by no means commonplace. Challenging behaviour is mostly associated with boys aged 8 to 9 and 12 to 15, and most often with boys with SEN and those from low-income families. Research in Germany shows a low incidence of challenging behaviour in schools, mainly involving boys aged 11 to 15 , usually from low-income families among whose adult members anti-social behaviour is common; many of the pupils concerned have repeated a year of schooling. Figures for the proportion of pupils in Scandinavian schools with challenging behaviour are substantially higher, at $11 \%$. This higher level is hard to explain; differences in perceptions of what constitutes challenging behaviour may well account for it.

14. University of Birmingham research commissioned by Ofsted for this survey indicates that when behaviour is discussed in schools there is little agreement as to the meaning or use of terms to describe challenging behaviour. ${ }^{3}$ Perception of challenging behaviour is relative and is conditioned both by the context in which the behaviour occurs and by the observer's expectations. There is, however, widespread 
agreement that two types of behaviour are challenging, whatever the particular circumstances. The first is overtly aggressive behaviour: physical acts such as biting and pinching, throwing furniture and assaulting people. The second is aggression that is mainly verbal, for example, streams of abuse, temper tantrums, and invasion of personal space intended to be threatening. The second type includes behaviour which defies teachers' authority in refusing to follow instructions.

15. Very few instances of serious misbehaviour in schools involve police investigation and judicial proceedings. The great majority of the incidents classified as youth offending take place somewhere other than in schools, although some take place in school time.
16. A survey undertaken in 2003 on behalf of the Youth Justice Board showed that youth offending in all contexts showed a slight decline over the previous two years. Research commissioned by the Board provides a good understanding of the factors in young people's lives which make offending more likely. These factors are:

- aggressive behaviour by the young person, including bullying

- family conflict and breakdown

- low achievement beginning in primary school

- lack of commitment to school, reflected in truancy

- peer involvement in problem behaviour

- the availability of drugs. 


\section{Behaviour in the settings visited}

17. In this survey, $\mathrm{HMI}$ visited 78 settings of very different types: early years provision; mainstream primary and secondary schools; maintained and independent special schools; PRUs; secure training centres; general further education (FE) colleges and independent specialist colleges. $^{4}$

\section{Types and extent of challenging behaviour}

18. The visits showed that the number of children and young people identified as showing challenging behaviour varies considerably between settings, even among those serving broadly similar communities, and reflects inconsistency in the use of the term.

19. Reports of the numbers of pupils showing challenging behaviour varied from very few to up to $40 \%$ of pupils in some early years settings and up to half in some of the primary and secondary schools. One PRU reported that none of its pupils had challenging behaviour, while others reported that over three quarters did. In the special schools visited, numbers vary from very few to all pupils on roll. Schools for pupils with EBSD and schools for pupils with SLD, as well as some for pupils with autistic spectrum disorders (ASD), tend to regard all their pupils as challenging. In schools for pupils with moderate learning difficulties (MLD) and a wider range of needs, proportions fall to an average of $10 \%$. By comparison, the proportion of students showing challenging behaviour in general FE colleges is very low, while, not surprisingly, in independent specialist colleges catering in particular for students with SLD and ASD the proportion is reported as high and growing.

20. Schools visited reported an increase in the number of pupils displaying behaviour related to medical needs, in particular those medically assessed as having ASD. The behaviour of these pupils may be verbally and physically aggressive, disruptive, withdrawn or sexualised. Many display a lack of awareness for their personal safety. In some special schools and independent specialist colleges many pupils with ASD and SLD present challenging behaviour on a daily basis within environments equipped to meet their needs.
21. A small number of pupils in about half the settings visited are withdrawn, anxious or depressed. These characteristics are most commonly reported by special schools, PRUs and secure training centres. Withdrawn behaviour that may indicate the onset of mental illness is often difficult for staff in schools and colleges to detect. It can go unnoticed in the classroom, especially when other groups present more disruptive behaviour. The University of Birmingham research indicated that pupils displaying withdrawn, anxious and depressed behaviour were potentially underidentified in all types of setting. Incidents of self-harm, usually involving very small numbers of pupils, occur in about a third of primary, special schools and PRUs and in over half of secondary schools. There are isolated incidents of sexualised behaviour in early years settings, in about a third of primary schools and half of secondary schools. This type of behaviour is more common in three quarters of PRUs and almost all special schools.

22. In one in five of the secondary schools visited gang culture is perceived to be widespread, although few schools had firm evidence of it. There were instances of the carrying of knives and other potential weapons reported in less than half the secondary schools and PRUs and in about half of the colleges visited. The prevalence of gang culture and weapon-carrying clearly varies considerably from one area of the country to another.

23. Drug abuse is a daily challenge in some of the settings for older pupils visited, more often PRUs and colleges than schools. In most secondary schools there are drug-related incidents at least once a term.

\section{Characteristics of learners showing challenging behaviour}

24. This survey confirms that boys are more likely than girls to be defiant and both physically and verbally abusive. This is true from primary to further education. In general FE colleges, the majority of more difficult students have EBSD and are aged 15 to 16 . Loud and raucous behaviour by boys is often a focus of teachers' attention, while inappropriate behaviour by girls is sometimes unnoticed or 
ignored. In schools, units and colleges girls predominate in instances of self-harm, depression and eating disorders.

25. Many of the pupils with the most challenging behaviour in schools, units and colleges have joined at times other than the usual point of admission. As pupils move in and out of different schools and units their learning is disrupted and they have difficulty forming relationships with peers and staff. Most affected are those schools in coastal towns and those serving social-housing estates; in these cases, parents move frequently throughout their child's school career. To engage, motivate and involve pupils who have little sense of belonging to a community demands a great deal of special effort by staff in schools; some are more able to supply the effort than others.

26. The survey shows that many of the pupils showing challenging behaviour in early years settings, schools and PRUs are from troubled families or are in public care. These vulnerable pupils are more likely to display difficult behaviour when they feel that responses to them by staff or other pupils are insensitive or derogatory.

27. Irregular attendance is an issue for a significant number of pupils with challenging behaviour in just under half the secondary schools and PRUs and about one third of the schools for pupils with EBSD. This leads to breaks in learning which affect pupils' behaviour and the development of positive relationships with staff and peers.

28. Pupils with SEN that require 'school action' or 'school action plus' or those who have a statement of SEN form at least one third of the pupils identified as having behavioural difficulties in the secondary schools visited. In the primary schools few of those identified have a statement for EBSD but about one third require 'school action' or 'school action plus'. Despite DfES guidance about the placement of pupils with statements in PRUs there are many such pupils in units. In three quarters of the PRUs, between $20 \%$ and $50 \%$ of the pupils with the most challenging behaviour have statements for EBSD and a significant number have been excluded from day and residential special schools. Increasingly, pupils placed in PRUs are younger, with more 5 to 7 year olds needing part or all of their education off-site.

29. In most of the primary schools only a small proportion of pupils with challenging behaviour are from minority ethnic groups. The proportions are higher in secondary schools and PRUs and in some of the special schools in inner-city areas.

30. In over half the primary, secondary and special schools and in three quarters of the PRUs some pupils are on medication as a result of their difficult behaviour.

Numbers vary from a few in the primary schools to 10 or more in some of the secondary schools. In some of the SLD and EBSD schools up to two thirds of pupils may be on medication. The number is also high in the secure training centres.

31. In over half the secondary schools visited, about half the EBSD schools and PRUs and one fifth of general FE colleges, a small proportion of pupils with the most difficult behaviour are reported as being involved in criminal proceedings.

\section{A significant proportion of pupils with challenging} behaviour have poor language and social skills and limited concentration spans. This association is evident in all the early years settings and in three quarters of primary schools visited. Difficulties, especially in literacy, often begin early and continue into secondary education and beyond. Two thirds of pupils who have been excluded from school have reading ages two to three years below their chronological age when they begin secondary school and thus struggle to read and comprehend material in lessons. They also tend to write badly. 


\section{Action to manage and improve behaviour}

\section{Consistency of approach}

- Inspection and research confirm the importance of consistency in approach by staff.

- Strong leadership and management are crucial to the effective management of behaviour. Clear direction and support to staff are keys to maintaining a positive ethos in which each pupil is valued and respected and, where necessary, learns to manage and improve their behaviour.

- A thorough induction programme helps schools with a high staff turnover to ensure consistency in approach.

- Regular training, focused on classroom practice, combined with in-depth appreciation of child and adolescent development, is central to understanding and managing behaviour.

- Schools that use information systems well to monitor pupils' behaviour are best placed to take speedy and effective action.

\section{Policies on behaviour}

33. Most of the schools and colleges visited have behaviour policies which set out expectations clearly. In two thirds of the schools, almost all the PRUs and independent specialist colleges, and about half the general FE colleges, the policy is implemented consistently by staff.

34. In a small number of the schools, policies are over-complex, do not promote consistency of expectation or do not emphasise the encouragement of positive behaviour. In the general FE colleges, systems are not always followed consistently by all faculties. Children and young people recognise the importance of rules and sanctions being consistently applied and often resent it when this basic principle is not observed. When there are inconsistencies, those who have more difficulty in moderating their own behaviour are unclear about boundaries.

\section{Hairdressing students at a general FE college are} encouraged to develop their own group rules at the beginning of the course. They devise an incentive system in which points are awarded for attendance, behaviour and achievement. The students determine who gets points, and these are tallied monthly. Winning students are rewarded with treatments in the hair and beauty salons and are put forward for the 'Student of the Year' award in that vocational area.

35. A negative emphasis in behaviour policies often results in a focus on dealing with problems after they have occurred. In the schools in which such emphasis is evident, too little consideration is given to the changes needed to promote good behaviour, notably improving the quality of teaching and developing an appropriate curriculum.

36. In the secondary schools visited, incidents of permanent exclusions were broadly in line with the national average but in a number the rate of fixed-term exclusions was very high. In a small proportion of the schools, exclusion is used as a way of enabling teachers to cope more effectively with difficult behaviour. This does not necessarily enhance teachers' confidence and ability to manage poor behaviour.

\section{Ethos}

37. This survey indicates that, in all early years settings and at least two thirds of primary and secondary schools, a positive and consistent ethos is promoted by the headteacher and senior management team, reinforced by staff and understood by pupils. There is close liaison with parents.

38. In early years settings this creates a secure environment where children thrive, develop confidence and begin to take responsibility for their own actions. This generally has a positive impact on their attitude to learning. High expectations for behaviour are shared with parents so that there is consistency between home and school.

39. A school's ethos provides the context within which children feel secure, know they are valued as individuals, are safe from emotional and physical harm and are able to discuss their interests and voice their fears in a supportive atmosphere. The development of a school's ethos falls to the senior management team but its growth and maintenance depend on the involvement and co-operation 
of the whole staff. Inspection and research continually reaffirm the importance of consistency in the way staff themselves behave and act in and around the school. This particularly helps boys to behave better and achieve more.

\section{Boys' attitudes}

40. An Ofsted report on boys' achievement showed that: ${ }^{5}$

- the relationship between the ethos of a school and the achievement of its pupils is close. Boys tend to respond well to an ethos that encourages and stimulates high standards, that engages their interest and commitment, and that insists on good behaviour and close partnership with parents

- the importance of a clearly defined disciplinary framework is especially marked for boys. Boys respond best when there is a consistent and fair-minded approach to discipline, backed up by effective pastoral systems and learning support

- boys tend to respond well to teachers who set clear limits and high expectations, direct work strongly, show enthusiasm for their subjects, use humour and reward good work. There is evidence that boys are rather less inclined than girls to learn from indifferent teaching.

41. The report went on to say that, although there is nothing as clear-cut as 'a boys' learning style', many schools have found certain approaches to be particularly helpful. For example, although many boys are willing to contribute orally, they can be helped to become more reflective in their replies. Their motivation can be enhanced by giving them greater access to computers for interactive learning or to help them improve the presentation of their work. Boys often respond better to lessons that have a clear structure and a variety of activities, including practical and activitybased learning, applications to real-life situations and an element of fun and competition. Many boys find it helpful to be given short-term targets and feedback that focuses on how they can improve.

\section{Support for staff}

42. The most difficult behaviour is almost always managed well in schools where strong senior managers give clear direction and reassuring support to staff. These effective leaders monitor the management of behaviour. The regular presence of senior managers around the school is seen by teachers as important in developing a sense of calm and order and enabling managers to understand the difficulties with behaviour that teachers face. Regular opportunities are organised so that staff discuss behaviour issues and have opportunities to learn from colleagues and to observe good practice. A strong staff team is created in which the emphasis is on mutual support. In the majority of the schools visited staff are well supported in understanding and responding to difficult behaviour. However, in a small number of the schools, mostly secondary and special schools, staff feel that they receive inadequate support.

43. Almost all the secondary schools visited had lost at least $10 \%$ of their staff in the course of the preceding year. In one in five, the figure was $25 \%$. In over half of early years settings, special schools and PRUs, between one and three posts are filled by temporary teachers. In the smaller PRUs this represents up to half the staff. These figures are higher in almost all secondary schools. High staff turnover and a significant proportion of temporary teachers can lead to inconsistencies of approach towards pupils with more challenging behaviour.

44. Good-quality written guidance - for example, in staff handbooks - helps new staff to come to terms quickly with the standards and expectations of the school. However, written documents need to be supported by a thorough induction programme if expectations are to be consistently reinforced and a positive ethos maintained.

45. Most of the schools and units visited have policies and procedures for staff induction. In early years settings and PRUs in particular, induction usually includes team teaching, training and mentoring. For example, in one PRU visited, the rapid turnover of staff has had little impact on pupils' behaviour because induction is thorough and expectations consistently reinforced. 
46. Arrangements for the induction of new staff are less consistent in other settings. Where the number of new teachers is high and where the recruitment of middle managers is difficult, mentoring and induction arrangements for new staff are not always followed. In some secure training centres staff are initially employed on a temporary contract. They work alongside others for nine weeks as they are inducted and trained, particularly in behaviour management. Similar arrangements exist in some independent specialist colleges; programmes consisting of observations, attending training courses and sharing common language often last for three months.

\section{Staff training}

47. Regular training that links classroom practice to an understanding of how children develop socially and emotionally is central to the effective understanding and management of behaviour. In the schools which have difficulty managing behaviour, more systematic training for headteachers and senior staff is needed.

48. The standards for qualified teacher status introduced in 2002 increased the emphasis on training in behaviour management. Trainees have to demonstrate that they:

- know a range of strategies to promote good behaviour and establish a purposeful learning environment

- set high expectations for pupils' behaviour and establish a clear framework for classroom discipline to anticipate and manage pupils' behaviour constructively, and promote self-control and independence.

49. Nevertheless, newly trained teachers often report that their initial training contained very little specific guidance as to how to understand and manage pupils' difficult behaviour. In both initial teacher training and in-service training, more emphasis is needed on child and adolescent development and the application of behaviour management strategies. This requires more than one or two sessions and needs to be seen as the start of a longterm programme of training which extends over the teaching career. LEAs have an important role to play in organising or facilitating training focused on applying knowledge about effective practice and management. Too often, school and LEA training activities react to a particular difficulty rather than forming part of a planned programme designed to prevent difficulty.

50. Two thirds of the primary schools in the survey provide suitable training in managing and improving difficult behaviour for all staff, including supervisors. Most of the secondary teachers have received some recent training but in schools where staff turnover is high, this is rarely repeated frequently enough. Not all schools and colleges involve all staff; in particular, teaching assistants and residential care staff are often omitted. In at least a third of the primary schools staff identified a need for more training, including for the management of challenging behaviour associated with ASD. An increasing number of secondary schools receive helpful support from behaviour professionals, funded through the DfES Behaviour Improvement Programme (BIP) or the Key Stage 3 Strategy. Many teachers in the PRUs have had little experience of working with pupils who have EBSD and, even in effective PRUs, training opportunities to develop strategies for working with the most difficult pupils are limited. In the FE colleges attendance at staff training is often voluntary and this can lead to differences in practice within and between faculties. Some of the college staff interviewed feel inadequately trained, for example in relation to physical restraint.

\section{Tracking and analysing behaviour}

51. Some of the schools carry out detailed tracking of behaviour and learning, identify pupils' needs and quickly take action. The more effective secondary schools, special schools and PRUs use this information to timetable lessons, to organise teaching groups, and to focus attention on subjects where teaching and learning is less effective. However, in many of the schools visited pupils' needs are identified too late and there is insufficient analysis of patterns of behaviour. In these schools it is usually a crisis that leads to belated action. 


\section{Appropriate adaptation of the curriculum}

- The majority of schools recognise the importance of using curriculum flexibility to capture pupils' interests, but this remains difficult for a small number of primary and special schools and a quarter of secondary schools.

- Additional government funding has allowed some schools to make adaptations to the curriculum which provide effective support to pupils with more difficult behaviour.

- The provision of out-of-hours activities and residential experiences offer good opportunities for learners to develop their social skills.

52. An appropriate curriculum is offered in all the early years settings visited, in almost all of the primary, special schools and PRUs and in about three quarters of secondary schools. In all the schools where the curriculum is limited and differentiation lacking, there is a high level of poor behaviour as pupils' interest, motivation and involvement decline.

\section{Early years settings}

53. In the early years settings visited staff usually discuss children's strengths and difficulties and plan the curriculum to meet their needs. Staff encourage children to select a broad range of activities then praise them for their choices. Time spent on particular sessions is sensibly short to enable children to focus and concentrate effectively.

\section{Primary schools}

54. In most of the primary schools the emphasis is on improving literacy and numeracy skills to enable access to all areas of the curriculum and so improve attitudes and concentration. Personal, social and health education (PSHE) and 'circle time' are used to develop social skills. In about one third of the primary schools, information and communication technology (ICT) and creative arts are seen as important motivators for pupils with more difficult behaviour. In a small proportion of the primary schools the curriculum is not adapted appropriately for some pupils. For example, the development of communication skills is not given enough emphasis in relation to pupils with ASD.

\section{Secondary schools}

55. In the majority of the secondary schools the content and organisation of the curriculum are recognised as important factors in capturing and holding pupils' interest, particularly those with difficult behaviour. However, for some, delivering a flexible curriculum remains difficult in practice.

56. In the secondary schools visited few modifications are made to the curriculum at Key Stage 3 apart from those for pupils who have been identified as having SEN, and especially for those with learning rather than behavioural difficulties. In some, but not all, of the secondary schools visited the curriculum at Key Stage 4 now includes a range of vocational and practically based courses. Often such a curriculum successfully meets the educational needs and career aspirations of pupils with behavioural difficulties.

57. The quality of teaching is strongly associated with attitudes and behaviour in lessons. Analysis of this relationship can play an important role in school selfevaluation by helping to pinpoint the subjects in which poor behaviour, as a symptom of low achievement and disaffection, is most evident. Nationally, the subjects in which pupils' attitudes and behaviour are currently least positive at Key Stage 3 are modern foreign languages, religious education and citizenship. These three subjects also feature in Key Stage 4, along with science and mathematics.

58. A number of the schools visited have received funding from Excellence in Cities or Education Action Zone programmes. This funding has generally been used well to adapt the curriculum to support pupils with more difficult behaviour. Links with colleges and local businesses have been extended and pupils spend time out of school acquiring practical skills. Learning mentors have been particularly effective in supporting pupils and helping them to manage and improve their behaviour. Learning support units provide a variety of activities designed to improve pupils' 
academic, social and behaviour skills. These are most successful when unit managers liaise closely with other staff and there are clear systems for re-integrating pupils into mainstream lessons. However, there are wide variations between schools. In the least effective units pupils spend too much time on pointless activities such as copying material provided by staff.

59. 'Nurture groups' have been established in some of the schools to meet the needs of pupils with EBSD. These have been established by staff trained to use specific techniques. The groups have clear boundaries and highly structured timetables and place emphasis on pupils' social and emotional development. They have proved effective in helping younger pupils to improve their concentration, behaviour and ability to learn.

\section{A Year 9 pupil with EBSD had poor attendance and} difficult behaviour from the beginning of Year 7. By Year 8 he attended irregularly, was disruptive and was increasingly excluded. The involvement of an education welfare officer and the adaptation of his curriculum to cut out French had little impact. A new approach was tried in which he followed a curriculum which centred on his strengths and interests. He attended a local community farm for two days a week and at school teachers created an individual timetable which included attendance at the learning support base. Since then he has not been excluded, his attendance at school has improved and he has not missed a day at the farm. He now has a weekend and holiday job at the farm and is about to start a course in animal care.

60. Some schools fail to realise the importance of the link between behaviour and the curriculum. In these schools, support in lessons is weak, little is done to adapt the curriculum at Key Stage 3, there is limited opportunity for work-related learning at Key Stage 4 and too little monitoring of the curriculum generally. In some of the schools difficulties recruiting staff have adversely affected the range of courses offered.

\section{Special schools and PRUs}

61. Most of the special schools and PRUs base their curriculum on a mainstream model but with adaptations to meet individual needs. In some, in particular in schools for pupils with EBSD, pupils with more difficult behaviour have opportunities to follow additional courses in music, physical education and art. Outdoor pursuits are often included either weekly or as residential experiences. These adaptations, when carefully planned, increase pupils' motivation, improve their attitudes and behaviour and help build self-esteem. However, in some of the special schools there is still insufficient focus on developing pupils' literacy and numeracy skills and thereby increasing their access to all areas of the curriculum.

\section{A PRU catering for up to 24 young mothers provides high-quality teaching through a broadly based and relevant curriculum with an emphasis on child} development. Expectations are high and relationships are good and as a result these young mothers make very good progress. Many exceed the GCSE grades predicted by their previous schools. Previously most had poor attendance, had disengaged with school and their behaviour challenged staff. In the supportive ethos of the $P R U$ they make very good progress in their personal development and instances of poor behaviour are rare. The high-quality on-site nursery makes a valuable contribution to the regular attendance of these young mothers. They can focus on their learning, secure in the knowledge that their children are receiving good care.

\section{FE colleges}

62. In the general FE colleges visited the size and number of courses allows wide choice and there is sufficient flexibility for changes to be made once courses are underway. Good progression opportunities exist from programmes followed by 14 to 16 year olds.

63. The curriculum in the independent specialist colleges is well adapted to suit the needs of the students; for example, there is a focus on developing independence and communication skills. 


\section{Out-of-hours activities}

64. Some of the schools, in particular secondary schools, have found that a good range of additional activities increases interest and better engages poorly behaved pupils, a message underlined in the Ofsted report, Improving City Schools. ${ }^{6}$ In about half the primary schools, pupils have the opportunity to take part in extra activities during and after the school day and to go on a residential trip. In some of the secondary and special schools summer holiday courses prior to admission to Year 7 offer good opportunities for pupils to get to know their peers and develop their social skills. In special schools there are more opportunities for pupils to take part in residential experiences but fewer outof-hours activities because of difficulties with home-toschool transport. The secondary schools, in particular those which are specialist schools, increasingly offer a wide range of activities at lunchtimes and after hours.

The school's designation as a sports college has led to an increase in the activities offered, which number over 100. Pupils are encouraged to find their own special interest and to become more closely involved. This has a positive effect on their attitudes, behaviour and their academic achievement across the curriculum, including those more difficult and potentially disaffected pupils.

\section{Effective teaching and learning}

The most effective teaching for learners with the most difficult behaviour is little different to that which is most successful for all groups of learners.

- Learning is best when staff know pupils well and plan lessons which take account of the different abilities, interests and learning styles.

- A positive classroom ethos with good relationships and strong teamwork between adults encourages good behaviour.

- Late starts to lessons, disorganised classrooms, low expectations and unsuitable tasks allow inappropriate behaviour to flourish.

- Pupils often react badly when staff show a lack of respect for or interest in them.

\section{Link between teaching and behaviour}

65. The Elton report, Discipline in schools, identified $80 \%$ of disruption in schools as being 'directly attributable to poor classroom organisation, planning and teaching'. In most, but not all, of the settings visited in this survey, it is recognised that effective teaching and learning is a key to encouraging good behaviour and engaging those pupils who have the most difficult behaviour. The most effective teaching for learners with the most difficult behaviour is little different to the most successful teaching for others.

66. Inspection of schools in challenging circumstances reported, for example, in an update to Access and achievement in urban education - shows that deteriorating behaviour goes hand in hand with a decline in the quality of teaching. ${ }^{7}$ Among the factors that influence this are: changes of staff; lack of consistency of expectation; failure to plan lessons satisfactorily to meet wide ranges of need; and lack of variety in strategies to engage pupils in learning.

67. The visits in this survey found many illustrations, particularly in secondary schools, of the fact that the behaviour of the most difficult pupils varies between lessons and teachers. Pupils' attitudes, behaviour and achievement are best where staff know pupils well and plan lessons which are well matched to their abilities and interests and take account of their different learning styles. In these lessons the transition between activities is managed well. High expectations are constantly reinforced and staff give meaningful praise. Marking is positive and takes learning forward. Pupils assess their work and discuss their progress with staff.

68. Where teaching is effective for all pupils there is good teamwork between teachers and assistants. Assistants contribute to the learning of all pupils in the classroom rather than focusing only on individuals. Roles are clear and there is a shared understanding about the lesson content. Relationships between teachers and pupils are good; humour is used well, which helps pupils to enjoy lessons. The pace of lessons ensures all sustain concentration and motivation. Wherever possible, oral instructions are

${ }^{6}$ Improving City Schools (HMI 222), Ofsted, 2000.

${ }^{7}$ Access and achievement in urban education: ten years on, Ofsted, 2003. 
reinforced by visual clues and realistic time scales are set for each task. Questioning is highly effective. It is structured to match pupils' ability levels so that all are involved. Staff allow learners time to respond.

In story time for a group of six primary pupils the teaching assistant read a story aloud while the teacher observed the children and noted their responses. Interesting props were used to bring the story to life. A pupil with a short concentration span and poor social skills sat in a fairly calm manner for the introduction and first part of the story but soon became distressed as he was not actively involved. The teaching assistant quickly spotted this and deliberately asked him a question before he had time to demand attention through inappropriate behaviour. To answer the question he had to get up and select resources. He did this well, was praised for knowing the story and thanked for making a correct choice of resources. He smiled, returned to his seat and sat quietly for the rest of the story.

69. Pupils with the most difficult behaviour respond positively when classrooms are well organised, there is a cheerful greeting from staff on arrival and routines for the start and end of lessons are clear. Seating plans, especially in secondary and special schools, help pupils with the most challenging behaviour to settle quickly. Teachers who are effective in reducing unacceptable behaviour are quick to intervene and divert pupils' attention. They apply a variety of strategies to engage and hold pupils' interest and so minimise the impact of negative behaviour. When behaviour is more difficult they adopt a consistent and non-confrontational approach and they always show respect for pupils.

During a literacy session in a school for pupils with SLD one pupil became distressed, hitting his head on a table and kicking out. A teaching assistant sitting close to the pupil quickly intervened. She followed the clear guidelines for managing his behaviour, which consisted of removing him from the classroom. This was done rapidly but sensitively. After a short time the pupil returned to class where he settled down to work. After five minutes the pupil again became distressed and the same procedure was followed, this time by the teacher. The teaching assistant carried on with the story and the pupil soon returned in a calm manner. Throughout the session individual strategies for managing behaviour were implemented consistently and disruption for other learners avoided.

70. In schools where the link between good teaching and improving behaviour is not clearly made and pursued, incidents of difficult behaviour are more common. In particular, in the secondary schools visited, school procedures for managing behaviour are not always followed consistently in all lessons. Where disruption is more common lessons tend to start late, arrangements for entering the room are disorganised and pupils often wait too long in corridors at the start. Expectations are low and the tasks, which tend to be unimaginative, are too simple or too difficult, especially in relation to pupils' capability in literacy. Often teachers give too many oral instructions so pupils become confused. Lessons seem long and there are few opportunities for learners to explore and develop their own ideas. In some of the general FE colleges inappropriate resources are used which are outside students' life experiences.

71. In many settings, there are cases of limited or unhelpful oral and written comments being given to learners about their work. In a small proportion of the schools some staff show a lack of respect by shouting at pupils, making fun of them, making personal remarks or using sarcasm. Some pupils react badly to such comments and to those who come too close, grab, hold or touch them even in mild restraint. Those with the most difficult behaviour often respond with verbal abuse. Poor behaviour escalates quickly, lessons are disrupted and the learning of all pupils is adversely affected.

A Year 2 lesson started late. Too much time was spent in organising the seating arrangements. The teacher failed to impose her authority on the class from the outset. As the lesson progressed the noise level started to rise. 
The teacher constantly told pupils to 'shush' but took no further action. Most pupils ignored this. The whole class activity of recognising definitions of words was too long and undemanding. Some pupils became distracted and lost interest which led to low-level but persistent disruptions such as pupils prodding and distracting each other, which gradually affected the learning of all.

\section{Well-focused pastoral support and guidance}

- Support and guidance tend to be good in schools where there is a strong sense of community and the staff regularly celebrate pupils' successes.

- The most effective pastoral support systems are those in which there is careful and regular tracking of pupils' learning and behaviour.

- The role of the tutor in secondary schools and colleges is of great importance in supporting those with the most difficult behaviour. However, the effectiveness of tutor support varies considerably.

\section{What good pastoral systems can do}

72. Pastoral systems that are effective for pupils with difficult behaviour are designed to support pupils both with their learning and their behaviour. Where there is a positive ethos in which staff regularly celebrate success, support and guidance tend to be good. A strong sense of community is established. Staff act as excellent role models and they talk with pupils about appropriate ways to behave and respond in difficult situations. Strong relationships are based on mutual respect and staff treat pupils fairly at all times. Teachers know their pupils well and additional support is given to pupils who require it. However, in many of the schools, even where numbers are small, not all staff know all the pupils and this can have a negative effect on the behaviour of the most difficult pupils.

73. In the early years settings and most of the primary schools staff support pupils well. In the secondary schools where support and guidance are good, all staff, from form tutors to senior managers, are involved in the process. In the special schools, PRUs, secure training centres and independent specialist colleges pupils often receive good support from their tutors which has a significant impact in helping them to improve their behaviour.

74. The effectiveness of the tutor system in secondary schools varies considerably. The daily meeting with the form or year tutor can provide an excellent opportunity to reduce tensions, sort out grievances and deal with situations well before they get out of hand. However, poorly managed sessions result in quite the opposite. Teachers require training to ensure that tutor time is used to the benefit of all pupils.

75. A good example of a school adapting its system better to support pupils was described by pupils in a school council meeting.

'The new tutor system is good. Since we moved to the new vertical tutoring system people have gotten to know older and younger pupils better. Older pupils help younger ones with homework and course work. Younger pupils feel they know the older pupils and the older pupils look out for the younger ones. It has helped in reducing bullying and with the peer mentors others have been involved in being 'buddies' of pupils who have got into difficulty. Prefects on duty also help reduce bullying and intimidation and there has been a change in who plays with each other. Football games involve more mixed ages than before. We still get incidents of bullying but we also get quicker and better support to deal with it.'

76. Pastoral systems are most effective when there is careful and regular tracking of pupils' social and academic progress. Setting precise targets and rewarding achievement for small improvements is an important part of the process. This happens on a daily basis in many of the special schools, PRUs and secure training centres, but less so in some of the secondary schools. Making time for effective pastoral support is critical and can lead to the effective resolution of repeated or extended difficult behaviour. 
In an inner-city area a child in public care with a statement of special educational needs had attended five primary and two secondary schools prior to the current placement. The pupil did not trust adults or understand his role in relationship to them. As a result, the boy did not modify his behaviour according to different circumstances and he frequently challenged what adults said. This led to innumerable detentions and fixed-term exclusions.

Learning mentors gathered and tracked information about his attitude in a range of situations and set up a 'buddy' scheme and other elements of a behaviour management programme. Staff were told about these and shown how to implement them and additional tutor time was allocated. A 'buddy' acted as a warning for the pupil, showing him when his behaviour or language was inappropriate. While the new system had only been in place a term, the daily round of confrontation has ceased and there has been only one incident since.

\section{Rewards and celebration}

77. Schools which support pupils well are quick to acknowledge and celebrate pupils' achievement and reward systems are applied consistently. Individual rewards help encourage pupils to take responsibility for their own behaviour. However, in some of the schools the focus is on negative behaviour and punishments rather than the rewarding of successes. In some of the general FE colleges achievement may be recognised in lessons but there are few opportunities for the wider sharing of successes.

In one school for pupils with EBSD a meeting is held for all staff at the end of the day where nominations are made for 'star pupils'. These nominations are used to encourage pupils who have behaved poorly but are trying to make amends with subsequent good behaviour. Pupils are praised publicly for their successes. The meeting is also used to reflect more generally on successes and difficulties encountered during the day and to review the strategies used.

\section{Responsibilities}

78. In many of the schools and units pupils are encouraged to take responsibility for every aspect of school life. Pupils carry out duties in their classroom at an early age and as they become older the responsibilities increase. In these schools teachers listen to pupils and involve them in whole-school decisions, for example, through the school council. Often they develop school and class rules and work alongside staff in setting and reviewing their own targets. 'Circle time' is used well in many of the primary and some of the secondary schools to promote school rules and develop strategies to enable pupils to take responsibility. Some of the schools have 'buddy' or peer mentoring systems which support pupils with the most challenging behaviour well. The involvement of pupils in supporting each other could be developed further in many schools.

The school has a centre for nine pupils with ASD. On admission to the school each pupil is assigned two 'buddies' from Year 6. These buddies support the pupil at assemblies and playtimes. Buddies take their responsibilities seriously and show pride in being selected to hold these privileged positions. Their work is carefully and sensitively supervised by adults. Buddies help pupils settle in and to remain calm at difficult times.

79. Some of the secondary schools successfully use 'restorative justice' to help pupils take responsibility for their own behaviour. However, a significant number of schools do not encourage pupils to take responsibility or to contribute to decision making processes. Consequently, these schools do not reach those pupils who are more easily disaffected by school.

\section{Good involvement of parents and carers}

Links with parents are most successful when parents are seen as partners rather than being blamed for the poor behaviour of their children.

- Parents welcome news of their children's successes as well as being informed about unacceptable behaviour. 
80. Overall, early years settings and primary schools are more successful in involving parents and carers than other settings. In early years settings staff maintain close links with parents; in many cases, communication between them takes place each day. This leads to a consistent approach at home and school and helps to improve pupils' behaviour.

\section{When this child started at nursery school, the mother} and practitioner discussed the concerns the mother had regarding her child's behaviour at home. The practitioner carried out some detailed observations of the child's play in the nursery and a team of nursery staff discussed possible strategies to manage the child's challenging behaviours. Staff regularly reviewed strategies with the mother. In the first term significant improvements in her child's behaviour were evident at home and school.

81. Where partnerships between parents and schools are strong, parents are involved as soon as concerns arise. Parents are seen as partners rather than being blamed for the poor behaviour of their children. The quality of information provided for them is good and the school or unit has a welcoming attitude towards them. Parents are encouraged to share in celebrating pupils' successes through achievement assemblies, home-school diaries and newsletters. In a small proportion of the early years settings and schools, voluntary agencies link well with home and offer valuable support to parents, pupils and school staff.

82. In some of the schools, most frequently special or secondary schools, there are weaknesses in the school's partnerships with parents. In some, parents are not made aware of behaviour policies. In a significant number of the secondary schools and some special schools, there is not enough emphasis on sharing with parents the successes of those with challenging behaviour so that most contact with them is about unacceptable behaviour. Not all of the special schools involve parents in the development of pupils' behaviour programmes; some merely inform parents of them. In the secure training centres, liaison with parents is often difficult because pupils come from a wide area and turnover of young people is high. Some of the general FE colleges take the view that parents can get involved if they want but it is their responsibility to do so. This is not always helpful in managing the behaviour of the most difficult students.

\section{A welcoming environment}

The quality of accommodation and of the learning environment has a significant impact on the behaviour of pupils and students; it should not be underestimated.

- Too few schools involve pupils in the design, maintenance and improvement of buildings to foster a sense of belonging and help to reduce vandalism.

- The lack of a quiet room which pupils can go to calm down is a handicap for those with more challenging behaviour.

83. The physical environment is generally better in the early years settings and primary schools than in the secondary schools, special schools, PRUs and some general FE colleges. It is good in less than one in five of the secondary schools and one in three of the PRUs.

84. The quality of the learning environment has a significant impact on the behaviour of pupils and students. A welcoming and stimulating environment tends to foster good behaviour. In many schools senior staff are aware of the impact that the environment has on behaviour and they seek to ensure that the cleanliness and brightness of accommodation are maintained. A high priority is placed on the condition of the buildings and much thought is given to how they are used. When damage occurs it is quickly repaired. High-quality displays celebrating pupils' achievement are evident in communal areas and classrooms.

85. Such an environment is likely to result in pupils having pride in their place of learning which, in turn, has a positive impact on their attitudes and behaviour. In the primary 
schools where play areas for younger children are well organised and supervised, poor behaviour is reduced. The schools which have organised lunchtime activities notice an improvement in behaviour. Those which try to involve pupils in the design, improvement and maintenance of the buildings find this fosters a sense of belonging, helps to develop positive attitudes and reduces vandalism. Too few of the schools involve pupils in this way.

The school has made the improvement of the environment a high priority. The playground has been redesigned with areas designated for team games, a shelter, painting area, rebound wall and benches. Pupils report that the playground is much better now and as a result their behaviour has improved.

86. A poor quality environment has a negative impact on behaviour. In some schools, mostly secondary, there are few displays of pupils' work and, where there are, the quality of displays varies noticeably between rooms. In some of the classrooms poor acoustics make it difficult for pupils to hear or to sustain concentration. Some of the schools are untidy and disorganised with unattractive communal areas and confusing layout. Long distances for pupils to travel between lessons often result in lateness and the need for corridor patrols to maintain order.
87. The external appearance of the PRUs visited is often poor; in some, but not all, staff make the best possible use of inadequate accommodation. In some special schools there is little space to store resources and equipment. In over half the EBSD schools there are no specialist teaching spaces for subjects including music, ICT, and design and technology which are subjects that often motivate pupils. In some of the special schools conditions are cramped; there is no quiet room in which pupils can calm down. This is a major weakness: pupils with challenging behaviour need a place to go to when their behaviour gets out of hand.

88. In a high proportion of the general FE colleges there are few displays of pupils' work, buildings are in a poor state of repair, there are too few recreation facilities for the numbers of students, and corridors are impersonal. These inadequacies have an adverse effect on students' attitudes and behaviour. 


\section{Effective support from other services}

- Only half the schools visited have established satisfactory relationships with an appropriate range of services.

- Even when partnerships are strong, evaluation of their impact is weak.

- The quality of LEA support provided for schools in managing difficult behaviour varies.

- Some LEAs co-ordinate multi-agency working effectively, but too many do not.

- Links with social services are weak in most early years settings and schools.

- Links with health services are undeveloped in at least a third of schools and units.

- Increasingly, schools have good links with voluntary groups and community projects which support pupils and their families well.

\section{Basis of multi-agency working}

89. Effective multi-agency work requires strong collaboration between partners. However, there are still many instances where the communication between schools and professionals is weak, and different organisations fail to provide well-informed, co-ordinated advice and treatment.

90. About half of schools visited have satisfactory working relationships with a range of agencies. Some of the schools have created a base where various professionals can work together and this helps to promote more successful joint working.

On an initial visit to a school the parents of a child with autistic tendencies discussed their child's needs. The school listened carefully to the parents, and sought advice and training prior to the child's admission. The class teacher carried out detailed on-going observations of the child's behaviour. In collaboration with the special needs co-ordinator and LEA Behaviour Support Service, she drew up possible interventions and behaviour management strategies. These were discussed with the parents so that a consistent approach was established at home and school. The close partnership that developed between the parents, school staff and other professionals enabled the child to make significant progress in a mainstream school.

One secondary school visited sets out deliberately to be at the heart of community improvement and to involve the community fully in the work of the school. The school makes extensive use of a wide range of partners and agencies which are used effectively to motivate pupils and improve behaviour. Work with agencies is coordinated well through a multi-agency co-ordinating group which meets monthly in the school and is chaired by a senior youth offending team worker. This contact ensures a consistent approach between agencies and the school. The work with agencies and partners is preventative and is having considerable success in creating the conditions where difficult behaviour rarely occurs in the school and the community.

91. In about half the schools procedures for working with external professionals are unclear and information is not shared effectively. Some of the secure training centres have few links with other agencies partly because admissions are from a very wide area. A good range of support is available to the general FE colleges, but systems for liaison and sharing information are not well established.

\section{LEA services}

92. Some local authorities co-ordinate multi-agency work effectively, but there are still many instances where professionals from different organisations fail to provide timely, well-informed advice and action. Some have joint funding arrangements and in a small number education and social services teams now work within a unified department. More needs to be done to create opportunities for joint training and closer working arrangements.

Support from a range of external professionals at this primary school is good. The LEA Behaviour Support Service provides good strategic advice to staff in the specific management of pupils with behaviour that challenges. The school nurse provides very good support to the school and individual pupils. She keeps in close 
and regular contact with the school and provides a valued link between the school and health professionals. She has strong contacts with local organisations and refers individual pupils to a variety of support services. There are only short waiting times when referral is made to Child and Adolescent Mental Health Services. This is partly because the school is making use of the full range of services in the local area, rather than going first to the mental health services.

93. The quality of LEA support for schools in managing difficult behaviour varies. LEA inspection reports for 2002/03 indicate that schools receive good or very good support for behaviour in only one in five LEAs. Many LEAs provide help through behaviour support teams of specialist teachers. This is generally appreciated by schools, although it is often thought insufficient.

94. Links between LEAs and early years settings are at least satisfactory. Some have inclusion officers assigned to them whose role is to co-ordinate additional support. About half the primary schools visited were satisfied with the LEA's behaviour and learning support services. One quarter work closely with them to establish effective procedures for managing difficult behaviour. For example, they promote whole-school behaviour management strategies or help teachers plan more appropriately for the range of needs and abilities. In one LEA, schools have developed good relationships with a crisis response service which carries out preventative work and gives schools confidence in managing pupils with the most difficult behaviour, but less than half of secondary and special schools have such links. Some report that LEAs have little expertise to offer in helping them to manage these pupils.

95. Most of the LEAs visited offer training for schools in issues related to managing behaviour. Some support primary schools in particular, by introducing approaches to promote pupils' emotional and social development. In some LEAs training and support is offered free of charge to newly qualified and temporary teachers but attendance on many courses is low.
96. The support which schools and units receive from educational psychologists varies. In this survey, all the early years settings, one in six primary schools and one in four secondary schools reported that support from educational psychologists is good. In these schools educational psychologists work with staff to develop whole-school policies, advise individual members of staff and assess and support individual pupils. However, at least half the schools reported difficulties in accessing support as a result of staff shortages. Almost one in five of the schools find the support received to be of little help in managing and improving the most challenging behaviour. In at least a quarter of the special schools and a larger proportion of the PRUs, support from educational psychologists is insufficient and most of their time is spent on statutory assessments. Links with education welfare officers are well established in only a small proportion of the primary schools and in about half the secondary schools.

\section{Social services}

97. Schools tend to feel poorly supported by social services, although they generally understand some of the difficulties these services face and appreciate the pressure on staff from the number of referrals. Evidence from the visits indicates that support from social services departments is inadequate in most of the early years settings and schools. Responses to requests are often too slow, and in at least half of settings representatives from social services failed to attend crucial meetings. Links with social services are good in the early years settings which are funded and run jointly by education and social services. In such cases staff have common procedures and information is effectively shared.

98. Nevertheless, when individuals at a local level within social services, school and the youth service are able to work together, substantial progress can be made through joint working.

A Year 10 refugee had been excluded from his previous school because of violent behaviour. The current school reviewed the reasons for the exclusion and, together with 
social services and carers, put together a package of support on admission. This consisted of the peer mentor attending all lessons with the pupil, daily contact with a learning mentor, counselling sessions, support from a Somali youth worker trained in anger management and active contact with the wider Somali community, which strengthened the school's position. The involvement of the social worker was crucial. Regular discussions between the carer, social services and school resulted in a common home/school approach to managing attitudes and behaviour. The school has used three fixed-term exclusions as a planned means to underpin the gravity of subsequent violent behaviour, but such incidents are now rare and the pupil is gradually improving with fewer examples of out-of-control behaviour.

\section{Health services}

99. In some areas of the country Child and Adolescent Mental Health Services (CAMHS) are now working closely with educational settings. Regional development workers have been appointed in all areas to improve joint working and to meet the standards set out in the Children's National Service Framework. By 2006, CAMHS aim to provide a comprehensive service which includes mental health promotion and early identification.

100. In this survey the numbers of pupils with difficult behaviour receiving support from CAMHS varied between LEAs. A few children in a small number of early years settings and a small number of pupils in about one third of primary schools receive CAMHS support. In half the special schools, mostly SLD and EBSD schools, up to 20\% of pupils receive support and in most secondary schools a small number fall into this group. The highest proportion of pupils receiving CAMHS support is in the PRUs. This figure varied from $5 \%$ in one primary unit, to over $80 \%$ in one secondary PRU.

101. In at least one third of all the schools and units partnerships with the health services are weak. There is little liaison between school and health professionals and referral times are often too long. In almost a third of the primary schools support from CAMHS is not available or response is slow. In about a third of the secondary schools support from school nurses is well established and pupils, for example those in danger of self-harm, receive good support. Some of the special schools, including independent special schools which cater for pupils with some of the most challenging behaviour, receive very little or no support from CAMHS.

\section{Connexions services}

102. Support from Connexions service personal advisers is good in about half the PRUs and secondary schools. On the evidence of this survey, it is better in the colleges than schools. Links with the police and with youth workers are good in almost half the secondary schools.

One college has established a multi-disciplinary behaviour team made up of senior academic staff, support staff, therapists and business support staff, chaired by an educational psychologist. The team maintains a high profile, manages the whole-college training programme, and reports to the senior management team. There is a strong emphasis on consistent approaches across the college. The team gathers detailed information on behaviour issues through the use of the behaviour reports and this information is used to inform strategy decisions.

\section{Voluntary organisations}

103. Some primary schools visited have effective links with voluntary organisations and where this is so working practices are well established and staff, families and pupils benefit from the counselling and training provided. About half the secondary schools have developed strong partnerships with counsellors, bereavement officers, drug intervention projects and other local groups which help them to manage the behaviour of the more difficult pupils.

At this secondary school a multi-agency review meeting is held and attended by heads of year, welfare officers, Connexions staff, learning support staff, the behaviour 
support service, the school counsellor and other professionals when appropriate. The group meets every two weeks to discuss individual pupils and make joint decisions about intervention strategies and involvement from other professionals. The deputy headteacher chairs the meeting, tracks referrals and identifies the key worker who will be responsible for pastoral support plans. The group also provides a training forum for heads of year and identifies areas for staff development. 


\section{Monitoring, evaluating and improving provision}

- Many schools and colleges have weak monitoring and evaluation procedures; too little regular tracking of behaviour takes place.

- Most LEAs carry out too little monitoring of how successfully schools manage difficult behaviour.

104. Wider inspection evidence indicates that schools which use information systems well are in a good position to analyse patterns of behaviour and take action accordingly. Overall, schools, units and colleges are poor at monitoring and evaluating their own provision and the impact of support from external agencies on the attitudes and behaviour of the more difficult pupils. This survey indicates that in a third of the secondary schools systems for identifying difficulties and tracking progress are weak.

105. Monitoring and evaluation tend to be better in the small early years settings than elsewhere. They are well established in less than half the primary and special schools, secure training centres, PRUs and FE colleges, and weak in at least a quarter. In the secondary schools procedures are good in only one third and weak in a similar proportion.

\section{Schools and PRUs}

106. In schools with well-established procedures for monitoring the outcomes of interventions for pupils with the most difficult behaviour, the process involves a range of staff, all of whom have clear roles and responsibilities. In some special schools there are isolated examples of good practice by individuals but in most this is not evident across the school.

107. An increasing proportion of schools have systems for tracking pupils' academic and personal development but only about a third of the secondary schools identifies and tracks pupils' difficult behaviour well. In a significant number of the schools behaviour targets are often vague and unhelpful to both pupils and staff. In some of the secondary and special schools, where pupils are on daily behaviour programmes, there is a lack of consistency among staff in discussing and recording pupils' progress. In many of the schools insufficient attention is given to variations between pupils' behaviour from one lesson, or one teacher, to another, or at different times of the day. Little consideration is given to the events leading up to episodes of particularly challenging behaviour. A lack of awareness of these factors can result in staff failing to make some simple adaptations which could help pupils manage and improve their difficult behaviour.

108. In over a quarter of the schools and units, monitoring is weak and senior staff or individual teachers are slow to share information which could benefit all and lead to changes in the strategies used to manage behaviour. As a result staff do not have access to well-founded information or strategies to assist them in managing pupils with more difficult behaviour.

109. However, when information over time is collated well and senior staff act decisively on the analysis of the information, remarkable change can be brought about.

When one girl transferred from primary to secondary school her history of organised bullying continued. The secondary school's efficient tracking system quickly identified when and where incidents occurred. This triggered intervention from the head of year who allocated learning and peer mentors trained in 'restorative justice' techniques to support the girl and her parents. It transpired the girl had been bullied herself. A support programme enabled the pupil to explore her own behaviour and linked her to a friendship network which minimised her need to threaten others. The change has been outstanding and led to a real improvement in selfesteem and a request from the girl to be trained as a peer mentor herself.

\section{Colleges}

110. Assessment and identification of needs are more consistent in independent specialist colleges than in the general FE colleges, where practice is variable within and between faculties. In the general FE colleges, staff are 
often unaware of pupils' difficulties at the time of entry either because of the poor quality of information provided by feeder schools or poor internal systems which preclude the sharing of information. Students joining courses later than the usual entry time often receive limited screening and support. The amount of information independent specialist colleges receive from special schools varies a great deal.

111. Where monitoring and evaluation are weak it is difficult to measure the value for money provided by additional interventions and hence finance can be wasted on strategies which have limited impact. In most of the schools little, if any, monitoring and evaluation is carried out on the impact of the work of external professionals. Where intervention from external agencies is well coordinated and managed by senior managers, monitoring and evaluation of the impact are usually more thorough. In a very small proportion of the secondary schools this allows staff to make judgements and comparisons about the value for money achieved from different services which support pupils with more difficult behaviour.

\section{Monitoring and evaluation by LEAs}

112. Most LEAs carry out very little monitoring of how successfully schools manage the most difficult behaviour. Data on permanent exclusions is collected and analysed and some of the LEAs analyse fixed-term exclusions. A smaller proportion look at information in detail to establish which groups cause concerns in which schools. As more schools carry out audits of behaviour, for example, through the Primary Strategy and the Key Stage 3 Strategy, so the information available to LEAs is increasing.
113. Evidence from a range of Ofsted inspections shows that the substantial funding which the DfES has provided to support provision in schools is proving generally beneficial. Among the examples are learning mentors and learning support units funded by Excellence in Cities. The training and inter-agency support for school staff provided through the Behaviour Improvement Programme are other examples. However, few LEAs and schools are good at quantifying evidence of the impact of provision, so there is often a lack of hard data on the effectiveness of initiatives.

114. In the last three years there has been a significant increase in the number of pupils attending independent schools for pupils with SEN. Many of the pupils admitted to these schools have EBSD or SLD, often with associated challenging behaviour. In some LEAs the data on pupils in out-of-area schools is not easy to access and little monitoring and evaluation of these placements take place. However, as LEAs attempt to reduce the use of out-of-area placements, this can result in pupils with the most difficult behaviour being placed inappropriately, usually in PRUs. In a quarter of the PRUs visited the inappropriate mix of pupils on roll had a negative impact on those pupils with more anxious, withdrawn and depressed behaviour. 


\section{Views of children and young people and parents and carers}

\section{Children and young people}

- Older pupils appreciate the good support they receive from assistants and mentors.

- They enjoy lessons in which teachers show them respect, offer interesting activities and make learning fun.

- Pupils and students feel they make better progress in their learning and behaviour when in small teaching groups.

115. The majority of pupils with more difficult behaviour find that having a particular member of staff whom they trust and can turn to in times of trouble helps them to manage and improve their behaviour. They appreciate having a quiet place to go to calm down when their behaviour has been unacceptable. In schools which manage difficult behaviour well pupils feel safe and are confident that issues such as bullying are dealt with swiftly and fairly. ${ }^{8}$

116. Pupils describe the good teachers as being those who respect pupils, offer interesting activities and make learning fun. A number say they like 'strict' teachers who give clear boundaries. Older pupils in mainstream and special provision appreciate the good support they receive from assistants and mentors, especially when support is discreet and staff are not always sitting by their side. Pupils feel their behaviour is better with teachers who have a good sense of humour and who 'deal with you privately'. They tend to prefer practical activities, in particular drama and PE. A few young people in secure training centres become bored with lessons where computer work constantly dominates. Such lessons 'drag on' and behaviour deteriorates. Learners like lessons which start with the teacher explaining the purpose and content.

117. Pupils in the PRUs appreciate the time staff give to explain things and support them. Some spoke of their difficult experiences in the past and their pride in the progress they have made where they are treated more like adults. Their relationships with others are good, whereas they had difficulties in previous placements. They feel that these units have given them a second chance.
118. The small size of groups was seen by pupils in the PRUs, special schools and students in some of the general FE colleges as an important factor in helping them to make progress in their learning and behaviour. In these settings they receive more individual attention, teachers know them better and good relationships can be established.

119. In the special schools most feel they are improving their learning and behaviour. Pupils, especially those in EBSD schools, appreciate the clear and consistent rules. In one third of these schools pupils enjoy the varied curriculum which includes residential trips and opportunities to experience a range of outdoor pursuits. In the secondary schools a small number feel that anger management, social skills sessions and youth clubs have helped them to improve. However, others would like more appropriate courses, such as those which provide work-related learning.

120. A significant number of pupils in the secondary schools dislike the inconsistent expectations shown by different teachers. They feel that some teachers do not explain things well, they shout too much, are too strict and seldom give any praise. In some lessons they feel they have been branded as a result of past behaviour and a punishment after each lesson is likely.

121. In a number of the secondary and some of the special schools and PRUs pupils mentioned the support they receive from outside agencies and in-school counsellors as particularly helpful in improving their behaviour and ability to learn. Meetings between parents, behaviour support workers and school staff are seen as important.

122. In about one third of the primary schools pupils know what they need to do to improve their behaviour and some talk about the strategies they use or the places they go to help them calm down. Most pupils in the secondary, special schools and PRUs know their individual targets and like the system for recognising and rewarding their achievement. In the PRUs and special schools they tend to enjoy receiving certificates to celebrate their successes. Some secondary school pupils feel the rewards themselves 
need to be better so that they are more motivated to improve their behaviour.

\section{Parents and carers}

In schools and units where difficult behaviour is managed well, parents and children feel well supported by staff.

- Some parents are concerned that there is insufficient liaison between external professionals and schools.

- Transition from primary to secondary education is a concern for a significant number of parents.

123. Almost all parents interviewed in schools and units where difficult behaviour is managed well spoke highly of the way in which staff supported them and their children. For younger pupils, daily contact through meetings, phone calls and home/school diaries keep parents well informed. This support results in good progress in behaviour and social skills both at school and at home. In the primary schools parents almost always feel they are listened to and respected. They appreciate the good support children receive from staff who provide positive role models and have high expectations for their children.

124. In the secondary and special schools and PRUs, almost all the parents interviewed were positive about the schools' supportive, approachable and flexible attitudes. Some of the parents feel that, rather than giving up on their child, teachers, assistants and learning mentors provided strong support. Communication between school and home is frequent and parents appreciate both the positive and negative reports. Many of the parents report improvements in pupils' behaviour and relationships at school and within the home. In a significant number of the PRUs parents are pleased with the progress their children make in examination courses and the way in which they are prepared for a return to mainstream education.
125. A small number of the parents describe good working relationships between schools and other agencies, in particular CAMHS and Connexions. Parents of pupils in the special schools mostly appreciate the all-round support offered to them and to their children. Parents of students in the independent specialist colleges are pleased with the support they receive in helping to understand their child's difficulty and how best to manage it. However, this positive picture is not replicated in the majority of settings.

126. Some common areas of concern exist. In the early years settings parents sometimes find that there is insufficient liaison between agencies, such as child and educational psychologists, and that insufficient information is transferred from outside agencies to receiving schools. In the primary schools and some of the schools for pupils with EBSD, a minority of parents describe a lack of sharing of information between professionals, for example, between CAMHS and schools. In a small number of the schools the strategies suggested by external agencies have not been implemented and parents are forced to follow this up, sometimes with limited success.

127. The transition from primary to secondary education is a concern for a significant number of parents. Where good relationships have been established with staff, parents have more confidence that the transition will be managed carefully and anxieties for themselves and their child will be reduced.

128. Some parents of secondary-aged children consider learning support units to be most effective in providing additional support for young people. They appreciate that exclusion is not used lightly. Other parents were aware that their child was not difficult in all lessons, only some. They explained that concentration was difficult when lessons were boring and restrictive. 

Alexandra House

33 Kingsway London WC2B 6SE

www.ofsted.gov.uk 